The Association has always endeavoured to keep its subscriptions to a minimum. In the fifties membership cost ten shillings a year. In the sixties this had risen to 21 shillings. In 1974 the subscription was $£ 2$ for consultants and $£ 1$ for others. In the eighties the subscription is $£ 5$ for consultants, $£ 3$ for others. Membership is, therefore, extremely good value. In 1977 the Association was recognised as a learned body for taxation purposes.

\section{Acknowledgements}

During the $\mathbf{4 0}$ years of its existence the Yorkshire Regional Psychiatric Association has held nearly 500 lectures. Most psychiatrists of distinction and many other professionals and personalities well-known and respected in their particular callings have lectured at some time to the Association. Like many academic bodies, the Association has never had the resources to offer speakers more than token fees beyond meeting their expenses. The Association has survived so far on the modest principle that an individual's being invited to give a lecture is an honour in itself, an opportunity to contribute to psychiatric education and to win recognition and regard among colleagues. Lecturers to the Association have fre- quently been able to develop their scripts for publication later elsewhere.

In the past the Association's lectures and study groups have helped to fill gaps in professional education. With the establishment of the Royal College of Psychiatrists, the introduction of approved schemes of training and the growth of academic departments, the role of the YRPA in professional education has diminished. It now complements professional training programmes and provides a forum where professionals can meet colleagues from their own and related disciplines. There they can discuss and share problems and reach less isolated, more relaxed and detached feelings about professional practice. The social element of the meetings can help to relieve and to put into perspective many of the tensions and pressures which professionals face in their day to day commitments.

The Association will be ever grateful to all who have helped to sustain its programmes, to lecturers, to sponsors for financial support, to the many people who have voluntarily and freely given their time as elected officers and committee members, to the Health Authorities which have granted it some concessions, and to a loyal membership which has attended the meetings.

\title{
Monitoring community care in York
}

\section{Giles Harborne, Registrar in Psychiatry; and Annette Henderson, Research Nurse, Bootham Park Hospital, York}

Up to 37,000 chronic mentally ill and mentally handicapped patients have been discharged from long-stay hospitals over the past ten years and nobody knows for certain where most of them are. This is one of the findings of the 1986 Audit Commission into community care which prompted Sir Roy Griffiths (1988) to state in his report on community care that:

"a system involving the assignment of a person in need of support to an individual career, so as to become his responsibility, is rarely made, even when highly applicable e.g. in the case of patients discharged from longstay hospitals."

He goes on to recommend that in the future, especially with the closure of large mental hospitals.

"No person should be discharged without a clear package of care devised and without being the responsibility of a named care worker. This is not simply an administrative or financial process: it is intended to be a thorough process of review to guarantee that there are carefully prepared plans to ensure an optimal quality of life for the individuals leaving hospital."

The subject of patient monitoring has already been promoted at top NHS management level in terms of assessing service quality and maintaining responsibility after the closure of long-stay hospitals. It is apparent that to implement these recommendations simple but effective methods of patient monitoring and management will be needed in every district as soon as possible.

The most substantial system reported so far, although still in the developmental stage, is the Friern Hospital schizophrenia follow-up study (Pantelis, et al, 1988). This is an expensive and specialised project which promises to provide a detailed and continuously updated assessment on all people with schizophrenia within the catchment area. 
The shortcomings of community care are once again in the public eye, with journalists pointing out that problems lie not just in the lack of resources, but also in the lack of defined responsibilities and therefore awareness of long-term needs, by the statutory bodies. There is, therefore, the added incentive of regaining public confidence in community care.

The following report represents our experience of initiating a monitoring system in York in 1986. This was in direct response to the report After Hospital commissioned by York Health Authority from Professor Jones, on the outcome of elderly confused and long-stay patients discharged into the York area (Jones, 1985).

Our two main objectives were firstly to meet the clinical need for identifying and following up priority patients at risk of relapse and neglect. As Professor Jones stated in her report: "What is needed is not a discharge plan but a community care plan".

Our second objective was to meet the managerial need for information on the movement of patients from hospital to community resources to ensure that they are not lost, and that gaps in the provision of services are quickly identified.

\section{York monitoring system}

York is an average sized Health Authority of approximately 250,000 population: half urban and half rural. The Mental Health Unit started its community care initiative in 1986 with sectorisation into four geographical sectors and the setting up of Community Mental Health Teams (CMHT). There were three psychiatric hospitals in the area; Bootham Park continues to provide acute services, Naburn closed in February 1988 and Clifton is due to close by 1992; there will be a range of new community based services developed in conjunction with Social Services to replace them.

A working group was set up by the unit manager comprising a research nurse, the unit information officer and a registrar in psychiatry, who have worked in liaison with the CMHT coordinators.

Consultation with members of staff has taken place both formally and informally. The issue of motivation has been a key point and depends upon keeping people well informed and generating information which they themselves will find valuable.

The system was started on a personal computer database but was moved to the Health Authority mainframe computer for greater flexibility of analysis; however, this is not essential for the operation of the system. There is part-time clerical support from the medical records department and all data are held and managed under the guidelines of the Data Protection Act 1984.
There are two parts to the system, a high risk list and an awareness list.

\section{High risk list}

The high risk list contains the names of patients placed at the discretion of members of the CMHTs, because the patient is felt to be at high risk of relapse or of becoming lost. They lack social support and are unlikely to contact the appropriate services when in need. The case manager decides the review interval which may be at three, six or nine monthly intervals. The review involves direct contact with the patient, and completion of a check-list of clinical details.

\section{Awareness list}

The awareness list is composed of patients from priority groups who are automatically placed on the list and cannot be removed, plus patients placed by the CMHTs who can be removed. The priority groups have been defined as follows:

(1) all patients over 65 discharged from hospital

(2) all patients discharged from the rehabilitation wards (attempts to define "revolving door" patients were unsuccessful and most of these patients pass through the rehabilitation service at some point)

(3) all patients attending the depot clinic

(4) all patients in long term day care

(5) community patients identified by the CMHTs.

Patients are reviewed at 12 monthly intervals and case managers are asked to complete the checklist using their present knowledge and verbal or telephone enquiries about the patient's wellbeing.

\section{Case managers}

The case manager is defined as a professional who accepts responsibility for surveillance and monitoring of the patient and is able to refer the patient when appropriate. This does not necessarily mean that they are actively involved in the treatment or supervision of the patient. For the different priority groups there are a number of identified case managers in each geographical area to which patients are allocated. The case managers identify themselves when placing high risk and awareness community patients on the list.

There has been an increasing diversification of case managers, so that no single group becomes overburdened, and they now include psychiatrists, CPNs, day care and day hospital organisers, officers in charge of residential units, social workers and GPs.

\section{Checklist}

The checklist briefly covers the following six areas on less than one side of A4 paper. 
(1) the patient's name, address and type of accommodation

(2) a key contact person either carer or involved professional, e.g. home help, district nurse, GP or generic social worker who can be contacted if the case manager has not seen the patient recently

(3) whether a diagnosis of dementia has been made

(4) whether recent contact with the patient has been made

(5) whether the patient has died, become a permanent in-patient on a psychogeriatric ward, or has left the Health Authority

(6) whether the supervision, finances, accommodation, and day care of the patient are satisfactory

On the high risk list, for the case manager's own use, there is a further section detailing the patients' present medication and a brief summary of present problems with proposed solutions.

\section{Upkeep of the system}

The system is now officially integrated into the normal working of the Mental Health Unit and the upkeep is divided into day-to-day and long-term activities. The majority of the day-to-day work is carried out by the clerical officer and is outlined below:

(1) identifying new patients in the priority groups, i.e. the discharge groups and new day patients

(2) production and distribution of follow up forms to case managers, and "chasing up" unreturned and incomplete forms

(3) inputting and updating data on the computer

(4) answering enquiries from case managers

(5) production and distribution of lists of all patients within each sector to be sent to the relevant CMHT at three monthly intervals. The CMHTs are then able to review their total numbers, the distribution between case managers and to reallocate patients to new case managers. They are also able to add or take off patients on the High Risk or the Community Awareness lists

(6) to arrange follow up of patients not contacted or definitely lost, by circulating lists of names to all the CMHTs, medical records and specific enquiries to GPs.

(7) cross-checking records for deaths and permanent admissions to psychogeriatric wards.

The long-term work is carried out by the working group and includes:

(1) preparing an annual report, the findings of which are summarised later in this paper

(2) informing MHU staff about the system and ensuring feedback of the results
(3) liaison with neighbouring Districts, Social Services and the voluntary services

(4) further development and refining of the system.

\section{Ethical considerations}

A number of concerns were raised by different professionals about the invasion of patients' privacy, and the holding and dissemination of personal details. It was pointed out that the information collected differed little from that already held on patients, that it is held and distributed in full confidentiality and the system is designed to benefit the patient.

Overall the operation of the system is similar to that of an automatic patient recall system, except that for the awareness patients the patient is not directly contacted, and for high risk patients where there is direct patient contact the patient can always decline to be interviewed.

\section{Results after the first 18 months of operation}

An annual report, the purpose of which is to review allocation of resources to the sector teams and identify gaps in the service, is produced. The results are summarised as follows and a full report is available on request.

\section{Positive points}

Early impressions gained from professionals indicate that there have been positive changes in the following areas. There has been a move towards preventive or anticipatory management of problems, for example the discovery of early behaviour problems in demented patients discharged to residential accommodation before the normal GP to consultant referral was implemented. On the whole, the extended follow up has met with a good response from patients, carers, residential homes and GPs who have been impressed by the long term interest and support of the Mental Health Unit.

The case manager system has helped to ensure that there is a yearly review of all the long term day and depot patients, which was not occurring previously.

In the CMHTs it has helped to bring the issues of responsibility, communication, distribution of workload and the relationship with primary care teams to the fore, and for the continued efficient operation of the system satisfactory solutions to these problems have to be found.

\section{Demographic information}

The information showed the difference across the sectors of patients and services. For example, in the 
TABLE I

Outcome of patients placed on the monitoring system, after a maximum of 18 months follow up

\begin{tabular}{lccccc}
\hline & $\begin{array}{c}\text { Over 65 } \\
\text { discharges }\end{array}$ & $\begin{array}{c}\text { Community } \\
\text { patients }\end{array}$ & $\begin{array}{c}\text { Day } \\
\text { patients }\end{array}$ & $\begin{array}{c}\text { Rehabilitation } \\
\text { discharges }\end{array}$ & TotAL \\
\hline Lost & 12 & 2 & 0 & 7 & 21 \\
Dead & 55 & 20 & 1 & 3 & 79 \\
$\begin{array}{l}\text { Permanent } \\
\text { In-patient }\end{array}$ & 32 & 6 & 0 & 1 & 39 \\
Remain in contact & 160 & 150 & 72 & 101 & 483 \\
\hline TotaL & 259 & 178 & 73 & 112 & 622 \\
\hline
\end{tabular}

sector most distant from York there was a relatively low use of hospital admission and a relative increase in out-patients. The effect of a specialist psychogeriatric service which covers just two of the four sectors was very noticeable, with a considerably increased prevalence rate especially of out-patients and nondemented in-patients in those sectors.

Age specific prevalence rates were calculated for dementia patients discharged from hospital. The figures showed a steady rise with age as expected from 1.5 per $1,000(65-74)$ to 7.5 per $1,000(75-84)$ and up to 14.5 per 1,000 in the over $85 \mathrm{~s}$.

\section{Patient outcome}

Table I shows that for the 622 patients who had been placed on the monitoring system in the first 18 months, 21 were lost, i.e. were unknown to health workers and could not be traced by contact with primary care workers, e.g. GP or Part III homes.

Seventy-nine had died, 28 of whom had been readmitted to long-stay wards. The death rate for the over 65 s discharged from hospital, as a percentage of discharges was $26 \%$ for patients with dementia and $16 \%$ for patients without, corresponding rates for community patients were $18 \%$ and $5 \%$ respectively. These rates, although referring to discharges rather than admissions, are comparable to those in the literature, for example Blessed \& Wilson (1982).

Of the remaining 483 patients still in contact, $41 \%$ had been seen in person by the case manager during the past year, in $23 \%$ the case manager had heard about them recently from other professionals, and in $35 \%$ information had been specifically obtained.

\section{Results of the patient assessment}

The assessment is a set of questions designed to raise issues for further investigation in the areas of patient accommodation, supervision, finances and day care. The case manager's subjective opinion of whether provision was satisfactory in these areas was recorded and in $4 \%$ of patients was found to be unsatisfactory.

Information on names and patient characteristics was then fed back to the CMHTs to find out if this was still the case. The same information was also passed on to the relevant management or task group for consideration in resource allocation.

Fifteen per cent of case managers stated positively that they did not know about their patients' circumstances and this percentage increased to $25 \%$ for the over 65 and rehabilitation discharge groups, showing that although only 21 patients were lost there is a large group of patients about whom little is known after discharge.

\section{Comment}

We have encountered a number of problems in the implementation of the monitoring system, the most important of which has been gaining the cooperation of staff and ensuring the feedback of results. Many issues of team working have been raised, along with ethical issues and worries about the subjective quality of definitions, e.g. defining high risk patients - who by definition will be difficult to follow up. Continuing education and imaginative solutions to problems, for example following up disorganised unco-operative high risk patients by contacting GPs, neighbours, etc., have helped to overcome most of them.

The system is expected to reach a steady state in three to four years time with around 1,000 to 1,500 patients on the list, a number not dissimilar to that of the old asylum provision for the area.

The system has helped clinicians in their follow up of patients, which has been shown to influence patient outcome favourably (Baldwin, 1988). It has helped the informed distribution of resources, and the maintenance of agreed priorities. In the long term it will help to reassure patients, relatives and the 
public that community care can work and be relied upon. It will also help raise the esteem of staff by indicating to them that the service they provide is successful and improvements that they may make in care will be recognised in the future.

Our conclusion is that long term monitoring of patients in the community is essential and that all Districts will have to develop some form of monitoring. It is likely that quite radically different solutions

\section{Acknowledgements}

We are indebted to the guidance received from $\mathrm{Dr}$ Peter Kennedy, District General Manager, York Health Authority, to the work of Ms Jenny Wheeler,

\section{References}

BALDWIN, R. (1988) Late life depression: undertreated? British Medical Journal, 296, 519.

Blessed, G. \& Wilson, I. D. (1982) The contemporary natural history of mental disorder in old age. British Journal of Psychiatry, 141, 59-67.

A Report to the Secretary of State for Social Services by Sir Roy Griffiths (1988) Community Care: Agenda for Action. London: HMSO. will emerge in different parts of the country and, in view of the lack of established examples, it is important that there is an open discussion of experience gained so far, and research into defining the most efficient and effective methods. Our method may be described as "quick and dirty", only providing indicators of areas that need further exploration. However, elaborate systems that take a long time to set up may be too late!

Ms Judy Hodgson and to the co-operation of patients and staff in the York Health Authority.

JONES, K. (1985) After Hospital: a study of long-term psychiatric patients in York. Department of Social Policy and Social Work, University of York.

Pantelis, C., TAylor, J. \& Campbell, P. (1988) The South Camden schizophrenia survey. Bulletin of the Royal College of Psychiatrists, 12, 98-101.

\title{
Conference report
}

\section{Royal Society of Health - Implementing Sections 135 and 136 of the Mental Health Act}

\author{
Geoffrey Wallis, Consultant Psychiatrist, Fulford Grange Hospital, Rawdon, Leeds
}

This meeting, which I attended to represent the Public Policy Committee, was held on 25 May 1988 in the Middlesex Hospital's Courtauld Lecture Theatre, where neither the air conditioning nor the sound amplification worked but neither defect greatly mattered. Most of the $\mathbf{5 0}$ or so people there seemed to be social workers. Some were policemen but I think I was the only doctor.

Mr Brian Smith, a member of the Council of the Royal Society of Health, whose multidisciplinary functions he outlined and membership of which he encouraged, said that this meeting had taken two or three years to materialise.
The speakers were Superintendent R. B. Stone, Sub-Divisional Commander for Devonport, of the Devon and Cornwall police, and Mr B. Lillington, who had both mental nursing and social work qualifications and was Chairman of the Southern Region of the Mental Health Act Commission. Both speakers were burly, brisk and avuncular. They quickly dismissed Section 135, Mr Stone saying that for it the police provided muscle only: so, despite its title, the meeting was all about Section 136.

Mr Stone said that Plymouth had high unemployment and 500 police officers for a population of a quarter of a million. The Nuffield Clinic contributed 